\title{
Randomized controlled trial of the effects of soy protein containing isoflavones on vascular function in postmenopausal women ${ }^{1-3}$
}

\author{
Sanne Kreijkamp-Kaspers, Linda Kok, Michiel L Bots, Diederick E Grobbee, Johanna W Lampe, \\ and Yvonne T van der Schouw
}

\begin{abstract}
Background: The incidence of cardiovascular disease increases after menopause, possibly because of the decline in estrogen. Soy protein, a rich source of estrogen-like isoflavones, is hypothesized to improve vascular function.
\end{abstract}

Objective: The objective of this study was to investigate whether supplementation with soy protein, a rich source of estrogen-like isoflavones, improves vascular function.

Design: We performed a 12-mo double-blind randomized trial to compare the effects of soy protein containing $99 \mathrm{mg}$ isoflavones/d (aglycone weights) with those of milk protein (placebo) on blood pressure and endothelial function in 202 postmenopausal women aged $60-75 \mathrm{y}$.

Results: Changes in endothelial function during the intervention were not significantly different between the soy and the placebo groups. After the intervention, systolic blood pressure increased in the soy group significantly more than it did in the placebo group; the difference in change was $4.3 \mathrm{~mm} \mathrm{Hg}(95 \% \mathrm{CI}: 0.3,8.4 \mathrm{~mm} \mathrm{Hg} ; P=$ 0.04) for systolic blood pressure, but only $2.0 \mathrm{~mm} \mathrm{Hg}$ (95\% CI: $-0.74,4.71 \mathrm{~mm} \mathrm{Hg} ; P=0.15$ ) for diastolic blood pressure. In the soy group only, systolic and diastolic blood pressure decreased and endothelial function improved in the equol producers, whereas systolic and diastolic blood pressure increased and endothelial function deteriorated in the equol nonproducers.

Conclusions: The results of this trial do not support the hypothesis that soy protein containing isoflavones have beneficial effects on vascular function in older postmenopausal women. Whether certain subgroups of women (eg, equol producers) do benefit from the intervention remains to be elucidated. Am J Clin Nutr 2005;81: 189-95.

KEY WORDS Isoflavones, soy, endothelial function, blood pressure, hypertension, postmenopausal women

\section{INTRODUCTION}

Cardiovascular disease is a major health concern in Western societies, and in women its incidence increases after menopause. This observation might be related to the sharp decline in endogenous estrogen production after menopause.

Isoflavones are estrogen-like compounds that are present in plant foods such as soy, nuts, and beans. A higher dietary soy intake has been reported to be associated with decreased cardiovascular mortality in Japanese women (1), but the consumption of soy and its associated isoflavones is 10-40-fold higher in
Asian countries than in Western countries $(2,3)$. Even at the low levels of consumption that are normal in Western countries, higher usual dietary isoflavone intakes were associated with decreased aortic stiffness (4). The trials published thus far are inconclusive; some trials have found improvements in endothelial function with isoflavones (5-7), whereas others have reported no changes $(8-11)$. Most of these studies were short in duration and enrolled small numbers of women.

Our aim was to investigate whether soy protein-containing isoflavones could improve endothelial function and blood pressure in postmenopausal women. We performed a 1-y doubleblind, randomized, placebo-controlled trial with soy protein in 202 postmenopausal women.

\section{SUBJECTS AND METHODS}

\section{Subjects}

The subjects were identified via the database of a breast cancer screening program in Utrecht. Between March 2000 and September 2000 we randomly assigned 202 women in the trial. Details of the study were published previously (12). We excluded women with conditions for which estrogens are contraindicated, women with an endometrial thickness $>4 \mathrm{~mm}$, current and recent (within past $6 \mathrm{mo}$ ) estrogen users, and women with a known allergy or hypersensitivity to soy or cow milk. The Institutional Review Board of the University Medical Center Utrecht approved the study protocol, and all participants gave informed written consent.

\section{Randomization and blinding}

After completing the baseline tests, the subjects were randomly assigned to the intervention or the placebo group in blocks

\footnotetext{
${ }^{1}$ From the The Julius Center for Health Sciences and Primary Care, University Medical Center Utrecht, Netherlands (SK-K, LK, MLB, DEG, and YTvdS), and the Fred Hutchinson Cancer Research Center, Seattle (JWL)

${ }^{2}$ Supported by The Netherlands Organization for Scientific Research (grant 014-91-024) and The Netherlands Organization for Health Research and Development (grant 2200.0048). The Solae Company (St Louis) provided the supplements.

${ }^{3}$ Address reprint requests to YT van der Schouw, Julius Center for Health Sciences and Primary Care, University Medical Center Utrecht, PO Box 85500, Room STR 6.131, 3508 GA Utrecht, Netherlands. E-mail: y.t.vanderschouw@umcutrecht.nl.

Received March 11, 2004

Accepted for publication September 17, 2004.
} 
of 10. A list of randomization numbers was computer generated. Each randomization number corresponded with 1 of the 2 possible interventions, and personnel not involved in the trial attached a label with the number to the identically looking boxes that contained soy or total milk protein. The research dietitian assigned randomization numbers to the subjects in order of enrollment into the trial. To assess the efficacy of blinding, the participants were asked at the end of the intervention to which group they thought they had been assigned to, the placebo or the soy group.

\section{Intervention}

The women were randomly assigned to receive either soy protein or total milk protein. The intervention consisted of $25.6 \mathrm{~g}$ isoflavone-rich soy protein containing $52 \mathrm{mg}$ genistein, $41 \mathrm{mg}$ daidzein, and $6 \mathrm{mg}$ glycitein (aglycone weights) in $36.5 \mathrm{~g}$ soyprotein powder (The Solae Company, St Louis) that could be mixed with food or beverages. The placebo (total milk protein) was identically looking and tasting and contained the same nutrients. Extra vitamins and minerals were added to the supplement for both groups (vitamin B-2, B-6, B-12, and D; folic acid; and calcium). One supplement was taken daily for a total period of $12 \mathrm{mo}$

A certified dietitian assessed the usual dietary pattern with the use of a food-frequency questionnaire at baseline and at the final visit. This questionnaire was validated (13) and marginally modified to capture dietary phytoestrogen intake. The dietitian counseled the participants on how to incorporate the supplement into their diets, and they provided recipes and suggestions. The participants were individually advised about which sources to decrease their protein intakes from to compensate for the extra protein intake from the supplement.

\section{Measurements}

At the physical examination we measured height (with the subjects shoeless) to the nearest $0.5 \mathrm{~cm}$ and weight to the nearest $0.5 \mathrm{~kg}$. A blood sample was drawn, and total cholesterol, LDL cholesterol, HDL cholesterol, and triacylglycerol were measured. Blood pressure and heart rate were measured with a Dinamap (Critikon Corp, Tampa, FL) on the right arm with the subjects in the sitting position. Blood pressure was measured at the screening visit, at randomization, and during the final visit. The baseline value was calculated as the mean of the measurements taken at the screening and the randomization visits. Waist circumference, just above the iliac crest, and hip circumference at the trochanter major (in $\mathrm{cm}$ ) were measured to estimate upper body adiposity. From the health questionnaire we obtained information about age at menarche, age at menopause, history of oral contraceptive use, use of hormone replacement therapy, use of cholesterol-lowering and antihypertensive medications, and smoking history. Physical activity was determined through the validated Questionnaire on Mobility in Elderly (14).

\section{Brachial endothelial function}

Endothelial function was measured with B-mode ultrasound imaging of the brachial artery by assessing the increase in artery diameter during reactive hyperemia (with increased flow leading to endothelium-dependent dilatation as detailed elsewhere) $(15,16)$.
In short, while the participants were in the supine position, a pediatric blood pressure cuff was positioned around the right forearm just below the elbow and where the electrocardiogram electrodes were placed. Blood pressure was measured. The participants were instructed not to talk during the measurements. With an ultrasound probe (7.5 MHz; Acuson Aspen, Mountain View, CA), the brachial artery was visualized. When a satisfactory longitudinal image of the brachial artery was obtained, the position of the transducer was secured. Three B-mode images showing the lumen diameter were frozen on the R-wave of the electrocardiogram for offline measurement of the baseline lumen diameter. Subsequently, the blood pressure cuff was inflated up to $50 \mathrm{~mm} \mathrm{Hg}$ above the participant's systolic blood pressure. After $4 \mathrm{~min}$, the cuff was deflated.

During the subsequent phase of reactive hyperemia, the image of the brachial artery was recorded every $15 \mathrm{~s}$ for $5 \mathrm{~min}$. The images were digitalized and subsequently analyzed with dedicated software (17). The dilatation was measured as the increase in diameter relative to the baseline diameter. The following equation gives the percentage change in diameter during the reactive hyperemia: (maximum diameter during reactive hyperemia mean diameter)/mean diameter $\times 100$. One person, blinded to the intakes of the subjects, performed all of the analyses, and a random sample of $10 \%$ was analyzed twice to assess reproducibility of the analyses. The Spearman correlation coefficient for repeated analyses was 0.81 . In previous studies performed in our Vascular Imaging Center, in which the same technique used to measure flow-mediated dilation (FMD) the SD within subjects was $2.6 \%$ FMD with a corresponding CV of $49 \%$. The CV of resting and maximum diameter was $8 \%(15,16,18-20)$.

\section{Compliance}

Plasma genistein and equol concentrations were measured in the blood sample taken at the final visit with the use of TR-FIA kits (Labmaster, Turku, Finland) $(21,22)$. Fluorescence was measured with the use of the Victor 2 model 1420 spectrofluorimeter (Wallac, Turku, Finland). Data were analyzed by using GRAPHPAD PRISM software (GraphPad Software Inc, San Diego). Intraassay and interassay CVs were $2.2 \%$ and $14.8 \%$, respectively. Subjects were considered to be equol producers if they had a plasma equol concentration $>83 \mathrm{nmol} / \mathrm{L}$ (23). The proportion of equol producers was $29.9 \%$. Equol-producer status could only be assessed within the soy group because an exposure to daidzein is required to determine equol status.

\section{Number of participants}

The planned number of subjects was 200, 100 in each intervention arm. This number was based on conventional assumptions of $\alpha=0.05$ and $\beta=0.20$ and a withdrawal from intervention of $25 \%$ of the sample. Assuming furthermore that soy isoflavones are as effective as is conventional hormone replacement therapy, we would be able to demonstrate an improvement of $32 \%$ in FMD. Improvements of up to $70 \%$ in FMD have been reported for conventional estrogen replacement therapy $(24,25)$. The mean and SD values from studies in our own Vascular Imaging Center are comparable with those in the literature.

\section{Data analysis}

We performed a closeout visit when a subject had participated for $\geq 1$ mo. Fourteen percent of the participants did not complete 
TABLE 1

Baseline characteristics of 202 postmenopausal women participating in the trial ${ }^{I}$

\begin{tabular}{|c|c|c|c|}
\hline & Placebo group $(n=102)$ & Soy group $(n=100)$ & $P^{2}$ \\
\hline Age (y) & $66.8 \pm 4.7^{3}$ & $66.6 \pm 4.8$ & 0.75 \\
\hline Weight $(\mathrm{kg})$ & $69.5 \pm 10.1$ & $71.0 \pm 11.3$ & 0.33 \\
\hline Diastolic blood pressure ( $\mathrm{mm} \mathrm{Hg}$ ) & $76.1 \pm 12.7$ & $74.4 \pm 10.8$ & 0.30 \\
\hline Systolic blood pressure (mm Hg) & $142.8 \pm 17.8$ & $138.9 \pm 16.7$ & 0.11 \\
\hline Current use of antihypertensive medication $[n(\%)]$ & $29(28.4)$ & $15(15.0)$ & 0.02 \\
\hline Current use of cholesterol-lowering medication $[n(\%)]$ & $16(15.7)$ & $13(13.0)$ & 0.59 \\
\hline Brachial endothelial function (\%FMD) & $4.4 \pm 3.4$ & $4.8 \pm 5.0$ & 0.58 \\
\hline BMI $\left(\mathrm{kg} / \mathrm{m}^{2}\right)$ & $26.0 \pm 3.4$ & $26.4 \pm 4.1$ & 0.39 \\
\hline Time postmenopause (y) & $17.9 \pm 6.2$ & $18.5 \pm 7.6$ & 0.52 \\
\hline Ever use of estrogens $[n(\%)]$ & $23(22.5)$ & $22(22.0)$ & 0.93 \\
\hline \multicolumn{4}{|l|}{ Smoking $[n(\%)]$} \\
\hline Current & $13(12.7)$ & $19(19.0)$ & 0.23 \\
\hline Former & $34(33.3)$ & $33(33.0)$ & 0.96 \\
\hline Fasting glucose $(\mathrm{mmol} / \mathrm{L})$ & $5.4 \pm 1.6$ & $5.5 \pm 0.9$ & 0.7 \\
\hline Cholesterol (mmol/L) & $6.1 \pm 0.9$ & $6.2 \pm 1.2$ & .60 \\
\hline LDL cholesterol (mmol/L) & $4.1 \pm 0.9$ & $4.2 \pm 1.0$ & 0.6 \\
\hline HDL cholesterol (mmol/L) & $1.5 \pm 0.3$ & $1.5 \pm 0.4$ & 0.6 \\
\hline Triacylglycerol (mmol/L) & $1.4 \pm 0.8$ & $1.3 \pm 0.7$ & 0.6 \\
\hline Lipoprotein(a) $(\mathrm{g} / \mathrm{L})$ & $0.24 \pm 0.28$ & $0.29 \pm 0.38$ & 0.30 \\
\hline
\end{tabular}

${ }^{1}$ FMD, flow-mediated dilation.

${ }^{2}$ ANOVA for continuous variables and chi-square test for categorical variables.

${ }^{3} \bar{x} \pm \mathrm{SD}$ (all such values).

1 mo of treatment or were unable or unwilling to participate in a final visit. All subjects who completed a closeout or final visit ( $86 \%$ of participants who entered the study) were included in the primary analysis, which was done on an intention-to-treat basis. In addition, we conducted a per protocol analysis, including only participants who had completed the whole treatment protocol (76\%). The results were analyzed with and without inclusion of women who were taking antihypertensive medications $(n=37)$. Linear regression analysis was used to calculate the difference in the baseline-to-final-visit changes between the soy and the placebo groups. Repeated-measures analysis of variance (ANOVA) was used to test the significance of the effects of soy compared with those of placebo.

Furthermore, whether the effect of soy differed across subgroups of postmenopausal years $(<14,14-22,>22)$, equolproducer status (only within the soy group), BMI ( $<25$ or $\geq 25$ ), and smoking (ever or never) was studied by looking at the effects of intervention in the specific subgroups. We tested this effect modification by adding interaction terms between intervention and group variable to the repeated-measures ANOVA model. Because equol-producer status could not be determined in the placebo group, because these women were not challenged with soy, we did not formally test the significance of the interaction between soy and equol-producer status, but performed a repeated-measures ANOVA to test the effect of equol-producer status within the soy-group.

\section{RESULTS}

Forty-nine $(24 \%)$ participants did not complete the trial for various reasons; the most important reason being gastrointestinal complaints and aversion to the taste of the supplement. The median duration of participation in the dropouts was $79 \mathrm{~d}$ (range: 4-285 d). There was no significant difference in the dropout rate between the 2 intervention groups ( $n=24$ in the placebo group and 25 in the soy group).

The baseline characteristics of the participants, by intervention group, is shown in Table 1. Despite randomization, there were some differences at baseline. The number of current smokers was somewhat higher in the soy group (19.0\%) than in the placebo group (12.7\%), and the use of antihypertensive medication was significantly lower in the soy group (15.0\%) than in the placebo group (28.4\%). All medical complaints during the intervention were recorded as adverse events; the most common complaints were gastrointestinal symptoms, such as constipation or heartburn. The number of adverse events was not significantly different between groups; both groups reported 2.5 adverse events. There were also no significant differences in the types of adverse events reported. Analysis of the food-frequency questionnaires indicated no significant differences in dietary intake patterns between the 2 groups.

Both groups reduced their intakes of protein and total energy as a result of the nutrients provided by the supplement (Table 2). Women were asked whether they thought they were in the soy group or in the placebo group; the responses were not significantly different between the 2 groups $\left(\chi^{2}=0.75, P=0.69\right)$, which confirmed that the blinding was effective. Genistein concentrations during the trial were significantly different between the soy and the placebo groups $(1259 \pm 1610$ and $55 \pm 101$ nmol/L, respectively; $P<0.001$ ), which demonstrated that compliance was good.

At baseline, both systolic and diastolic blood pressures were lower in the soy group than in the placebo group (systolic: $138 \pm$ 16.7 and $143 \pm 18.1 \mathrm{~mm} \mathrm{Hg}$, respectively; diastolic: $74 \pm 10.7$ and $76 \pm 12.9 \mathrm{~mm} \mathrm{Hg}$, respectively). The other vascular indexes were not significantly different between groups at baseline. After the intervention, the systolic blood pressure tended to increase in the soy group relative to that in the placebo group; the difference 
TABLE 2

Dietary nutrient intake at baseline and the final visit, excluding nutrients from the supplement ${ }^{l}$

\begin{tabular}{|c|c|c|c|c|c|}
\hline & \multicolumn{2}{|c|}{ Placebo group $(n=102)$} & \multicolumn{2}{|c|}{ Soy group $(n=100)$} & \multirow{2}{*}{$\begin{array}{c}P \\
\text { (final visit) }^{2}\end{array}$} \\
\hline & Baseline & Final visit & Baseline & Final visit & \\
\hline Isoflavones (mg) & $6.9 \pm 10.5^{3}$ & $6.7 \pm 9.5$ & $5.3 \pm 8.6$ & $4.9 \pm 8.0$ & 0.78 \\
\hline Coumestans (mg) & $2.4 \pm 4.0$ & $2.5 \pm 3.1$ & $1.4 \pm 3.2$ & $1.8 \pm 3.6$ & 0.38 \\
\hline Lignan precursors (mg) & $1.8 \pm 0.8$ & $2.0 \pm 0.9$ & $1.7 \pm 0.7$ & $1.9 \pm 0.8$ & 0.02 \\
\hline Total phytoestrogens (mg) & $12.3 \pm 14.5$ & $12.3 \pm 12.6$ & $9.4 \pm 11.3$ & $9.7 \pm 11.5$ & 0.86 \\
\hline Energy (kcal) & $2141 \pm 429$ & $2119 \pm 449.3$ & $1862 \pm 430$ & $1887 \pm 447$ & 0.72 \\
\hline Total protein $(\mathrm{g})$ & $103 \pm 22.3$ & $99.2 \pm 22.1$ & $81.3 \pm 18.4$ & $82.5 \pm 19.5$ & 0.69 \\
\hline Plant protein $(\mathrm{g})$ & $39.0 \pm 11.2$ & $38.9 \pm 11.6$ & $34.4 \pm 9.4$ & $35.8 \pm 11.2$ & 0.39 \\
\hline Animal protein (g) & $64.2 \pm 17.3$ & $60.7 \pm 18.6$ & $47.1 \pm 14.7$ & $46.9 \pm 14.7$ & 0.91 \\
\hline Fish (g) & $20.5 \pm 21.8$ & $10.5 \pm 10.0$ & $19.9 \pm 19.6$ & $12.3 \pm 11.7$ & 0.31 \\
\hline Total fat (g) & $76.3 \pm 22.7$ & $74.0 \pm 24.1$ & $71.9 \pm 24.2$ & $69.5 \pm 21.0$ & 0.49 \\
\hline Saturated fat $(\mathrm{g})$ & $31.8 \pm 11.3$ & $30.2 \pm 11.1$ & $31.8 \pm 12.6$ & $28.8 \pm 9.8$ & 0.09 \\
\hline Monounsaturated fat (g) & $28.0 \pm 9.2$ & $27.1 \pm 9.3$ & $26.2 \pm 9.3$ & $25.1 \pm 8.6$ & 0.42 \\
\hline Polyunsaturated fat (g) & $16.0 \pm 5.8$ & $16.3 \pm 7.5$ & $13.5 \pm 5.8$ & $15.2 \pm 6.7$ & 0.08 \\
\hline Carbohydrate (g) & $242 \pm 58.3$ & $244 \pm 62.8$ & $206 \pm 56.4$ & $214 \pm 59.6$ & 0.40 \\
\hline Fiber $(\mathrm{g})$ & $37.1 \pm 9.9$ & $38.6 \pm 10.4$ & $31.7 \pm 8.2$ & $33.5 \pm 8.8$ & 0.16 \\
\hline Alcohol (g) & $10.3 \pm 11.3$ & $10.9 \pm 10.7$ & $9.3 \pm 10.5$ & $10.9 \pm 11.0$ & 0.34 \\
\hline Calcium (mg) & $1742 \pm 566$ & $1606 \pm 521$ & $1319 \pm 483$ & $1212 \pm 393$ & 0.12 \\
\hline Vitamin $\mathrm{D}(\mu \mathrm{g})$ & $4.4 \pm 2.4$ & $4.4 \pm 2.2$ & $3.2 \pm 1.4$ & $3.5 \pm 1.6$ & 0.18 \\
\hline Vitamin C (mg) & $144 \pm 55.4$ & $152 \pm 72.2$ & $135 \pm 53.8$ & $132 \pm 53$ & 0.64 \\
\hline
\end{tabular}

${ }^{I}$ There were no significant differences between the 2 groups at baseline for any of the variables.

${ }^{2}$ Repeated-measures ANOVA for time $\times$ treatment interaction.

${ }^{3} \bar{x} \pm \mathrm{SD}$ (all such values).

in change was 4.3 (95\% CI: $0.3,8.4 ; P=0.04) \mathrm{mm} \mathrm{Hg}$ (Table 3 ). We repeated the analyses with baseline systolic and diastolic blood pressure as a covariate to adjust for baseline differences, but this did not change the results significantly (data not shown). When the women who were taking antihypertensive medication were excluded from the analyses, the differences were 3.8 (95\% CI: $-0.9,8.5 ; P=0.12) \mathrm{mm} \mathrm{Hg}$ for systolic and $1.1(95 \% \mathrm{CI}:-1.5,3.8 ; P=0.41) \mathrm{mm} \mathrm{Hg}$ for diastolic blood pressure (Table 3).
We found no significant differences in endothelial function between the 2 groups after the intervention. There was no significant interaction with BMI, smoking, or years postmenopause. In the soy group, systolic and diastolic blood pressure decreased and endothelial function improved in the equol producers, whereas blood pressure increased and endothelial function deteriorated during the intervention in the nonproducers of equol (Table 4). However, the differences between producers and nonproducers of equol was not statistically significant.

TABLE 3

Effects of a soy supplement containing isoflavones on vascular function in postmenopausal women ${ }^{l}$

\begin{tabular}{|c|c|c|c|c|c|c|}
\hline & \multicolumn{2}{|c|}{ Placebo group } & \multicolumn{2}{|c|}{ Soy group } & \multirow[b]{2}{*}{ Difference in change $(95 \% \mathrm{CI})$} & \multirow[b]{2}{*}{$P^{2}$} \\
\hline & Baseline & Final visit & Baseline & Final visit & & \\
\hline \multicolumn{7}{|l|}{ Intention to treat $(n=175)^{3}$} \\
\hline Diastolic blood pressure & $76.2 \pm 12.9$ & $74.5 \pm 12.4$ & $74.1 \pm 10.7$ & $74.4 \pm 14.1$ & $1.99(-0.74,4.71)$ & 0.15 \\
\hline Systolic blood pressure & $143.4 \pm 18.2$ & $139.9 \pm 18.1$ & $138.4 \pm 16.7$ & $139.2 \pm 18.2$ & $4.34(0.25,8.42)$ & 0.04 \\
\hline$\%$ FMD & $4.4 \pm 3.4$ & $4.4 \pm 4.0$ & $4.8 \pm 5.0$ & $5.1 \pm 5.4$ & $0.37(-1.48,2.21)$ & 0.69 \\
\hline \multicolumn{7}{|l|}{ Per protocol $(n=153)^{4}$} \\
\hline Diastolic blood pressure & $75.7 \pm 12.9$ & $73.7 \pm 12.2$ & $74.6 \pm 10.7$ & $75.1 \pm 13.9$ & $2.53(-0.41,5.47)$ & 0.09 \\
\hline Systolic blood pressure & $143.4 \pm 18.7$ & $139.1 \pm 18.5$ & $138.4 \pm 16.7$ & $139.7 \pm 18.2$ & $5.55(1.07,10.02)$ & 0.02 \\
\hline$\%$ FMD & $4.3 \pm 3.2$ & $4.5 \pm 4.0$ & $5.4 \pm 5.1$ & $5.1 \pm 5.7$ & $-0.43(-2.41,1.55)$ & 0.67 \\
\hline \multicolumn{7}{|c|}{ Excluding medication $(n=138)^{5}$} \\
\hline Diastolic blood pressure & $74.1 \pm 12.1$ & $72.2 \pm 11.9$ & $73.1 \pm 10.8$ & $72.4 \pm 12.4$ & $1.12(-1.54,3.79)$ & 0.41 \\
\hline Systolic blood pressure & $139.9 \pm 18.5$ & $136.0 \pm 17.5$ & $137.0 \pm 17.0$ & $136.9 \pm 17.0$ & $3.76(-0.93,8.45)$ & 0.12 \\
\hline$\% \mathrm{FMD}$ & $4.6 \pm 3.5$ & $4.2 \pm 3.5$ & $4.8 \pm 5.0$ & $5.1 \pm 5.3$ & $0.61(-1.62,2.84)$ & 0.59 \\
\hline
\end{tabular}

${ }^{1}$ FMD, flow-mediated dilation.

${ }^{2}$ Repeated-measures ANOVA for time $\times$ equol-status interaction.

${ }^{3} n=87$ and 88 for the placebo and soy groups, respectively.

${ }^{4} n=78$ and 75 for the placebo and soy groups, respectively.

${ }^{5} n=63$ and 75 for the placebo and soy groups, respectively. 
TABLE 4

Effects of a soy supplement on vascular function in the equol producers and the nonproducers in the soy group ${ }^{l}$

\begin{tabular}{|c|c|c|c|c|c|c|}
\hline & \multicolumn{2}{|c|}{ Equol nonproducers $(n=63)$} & \multicolumn{2}{|c|}{ Equol producers $(n=25)$} & \multirow[b]{2}{*}{ Difference in change $(95 \% \mathrm{CI})$} & \multirow[b]{2}{*}{$P^{2}$} \\
\hline & Baseline & Final visit & Baseline & Final visit & & \\
\hline Diastolic blood pressure & $74.5 \pm 10.7^{3}$ & $75.4 \pm 15.2$ & $73.2 \pm 10.2$ & $72.5 \pm 10.0$ & $-1.6(-6.2,3.0)$ & 0.48 \\
\hline Systolic blood pressure & $138.2 \pm 17.2$ & $140.8 \pm 19.3$ & $138.1 \pm 15.5$ & $135.1 \pm 15.4$ & $-5.6(-12.1,1.0)$ & 0.09 \\
\hline$\%$ FMD & $4.9 \pm 5.5$ & $4.8 \pm 5.6$ & $4.8 \pm 3.7$ & $5.9 \pm 5.2$ & $1.84(-1.37,5.06)$ & 0.26 \\
\hline
\end{tabular}

${ }^{1}$ FMD, flow-mediated dilation.

${ }^{2}$ Repeated-measures ANOVA for time $\times$ equol-status interaction.

${ }^{3} \bar{x} \pm \mathrm{SD}$ (all such values).

\section{DISCUSSION}

We did not observe a beneficial effect of a soy-protein supplement containing large amounts of isoflavones on vascular function, although effects limited to women capable of equol production cannot entirely be excluded.

To fully appreciate these results, some issues need to be addressed. The strengths of this study were the large sample size and the double-blind randomized design. The number of dropouts did not exceed $25 \%$, as prespecified in the power calculation; thus, the blinding was effective. Although randomization resulted in reasonably well-balanced groups, there were some differences between the soy and the placebo groups at baseline that could have influenced the results. We included baseline systolic and diastolic blood pressure as covariates in the analyses to adjust for these baseline differences, but this did not change the results materially. The number of women who used blood pressure-lowering medication was higher in the placebo group. In Table 3 we present results after all women taking blood pressurelowering medication $(n=37)$ were excluded, but this resulted in only small changes in the estimates. The same held true for the subgroup analyses for smoking (data not shown). Although imbalances in the groups, despite randomization, may have slightly influenced the precise estimates, we believe that this did not affected the validity of the overall results of this study.

The lack of an effect may have resulted because of noncompliance. Therefore, we assessed genistein concentrations in the blood sample taken at the final visit, and concentrations were markedly different between the soy and the placebo groups, which demonstrated that compliance was good.

The endothelium - the luminal layer of cells in the vascular wall-plays a major role in vascular function (26). Endothelial cells synthesize nitric oxide (NO) from L-arginine and molecular oxygen through the catalytic activity of endothelial nitric oxide synthase (eNOS). After its synthesis, NO is released, not stored. NO relaxes the vascular smooth muscle cells and inhibits platelet aggregation (27), inhibits leukocyte adhesion to endothelium (28) through inhibition of cell adhesion molecules (29), and inhibits vascular smooth muscle cell migration and growth (30). NO also inhibits the oxidation of LDL cholesterol (31) - a prerequisite for its scavenger receptor-mediated uptake by foam cells. Both estrogen and isoflavones were able to increase endothelial nitric oxide synthase messenger RNA concentrations (32), up-regulate the activity of the eNOS isoenzymes, and increase the released concentrations of NO (33-35).

In animal research, strong evidence of a cardioprotective effect of isoflavones exists. In ovariectomized rats, genistein $(0.2$ $\mathrm{mg} \cdot \mathrm{kg}^{-1} \cdot \mathrm{d}^{-1}$ subcutaneously for $4 \mathrm{wk}$ ) improved endothelial function (36), and the magnitude of this effect was similar to the effects of estradiol. In ovariectomized, spontaneously hypertensive rats, a soy-protein diet resulted in a lower mean arterial pressure when compared with casein feeding (37). In a similar experiment, a soy-protein diet was found to decrease the development of hypertension in male and nonovariectomized female rats (38).

In our study in humans we could not confirm such a cardioprotective effect of a soy protein supplement containing isoflavones. For blood pressure, some data from human research are available. Teede et al (10) reported a significant reducing effect on blood pressure of a soy-protein isolate (118 $\mathrm{mg}$ isoflavones) compared with casein after 3 mo in postmenopausal women $(n=$ $105)$ and men $(n=108)$ in a double-blind randomized trial. The difference in change during the intervention was $-3.9 \mathrm{~mm} \mathrm{Hg}$ for systolic blood pressure and $-2.4 \mathrm{~mm} \mathrm{Hg}$ for diastolic blood pressure, whereas in our trial the results were almost the reverse, $4.3 \mathrm{~mm} \mathrm{Hg}$ for systolic and 2.0 for diastolic blood pressure. The main difference between our trial and Teede et al's trial was the duration of the intervention ( 3 mo in the present trial compared with $12 \mathrm{mo}$ ) and the mean age of the participants (an average of $60 \mathrm{y}$ in the present trial compared with an average of $67 \mathrm{y}$ ). The active and the placebo interventions (soy-protein isolate and casein) in their trial were similar to the interventions in our trial. The conflicting results could have resulted from a chance finding in either trial. In a study of 25 men and 15 women with hypertension conducted by Rivas et al (39), the effects of a 3-mo intervention with soymilk were compared with those of cow milk; both systolic and diastolic blood pressure decreased after the soy intervention. However, several other trials showed no changes in blood pressure with soy protein $(6,40)$ or isoflavone tablets $(5,9,41)$. Further studies need to be conducted before the true relation between soy protein or isoflavones and blood pressure will be revealed.

For endothelial function, the same inconclusive results as for blood pressure are reported in the literature. The assessment of endothelial function on the basis of FMD is a complex task. Many physiologic factors influence endothelial function, which causes large variability (42). We found no statistically significant effect of soy protein on endothelial function. Teede et al (10) also investigated the effects of soy protein on endothelial function and found no effects in postmenopausal women, whereas endothelial function deteriorated in men. A tablet of $54 \mathrm{mg}$ genistein/d for 6 mo and $1 \mathrm{y}$, respectively, was reported to improve endothelial function in postmenopausal women $(5,7)$. Our supplement contained $52 \mathrm{mg}$ genistein/d. In a small 4-wk crossover study $(n=$ 18) with soy-protein isolate, endothelial function also improved; 
however, in 3 studies in postmenopausal women ranging from 2 to 8 wk in duration $(n=20-29)$, no effects were seen $(8,9,11)$. Our results are compatible with no effect or, at best, a very limited effect of soy protein on endothelial function.

Recently, the role of the metabolite equol produced from the precursor daidzein has received much attention (23). The intestinal flora produces this relatively strong estrogen agonist in only $\approx 30 \%$ of people after exposure to daidzein. In rodents this metabolite is formed in $100 \%$ of animals. This could, in part, be an explanation for the large discrepancy between human and animal research and, therefore, it was hypothesized that only the producers of this metabolite would benefit from interventions with soy protein. We assessed equol-producer status within the intervention group. We could not assess this in the control group because they were not exposed to soy. In the subgroup analyses we found a decrease in systolic and diastolic blood pressure and an improvement in endothelial function in the equol producers and an increase in systolic and diastolic blood pressure and deterioration in endothelial function in the nonproducers of equol. Because of the small numbers, these differences were not statistical significant; however, the findings do support the hypothesis that only a limited group of women might benefit from soy intervention.

In conclusion, the results of this large, double-blind, 12-mo randomized trial do not support the hypothesis that soy protein containing isoflavones has beneficial effects on vascular function in older postmenopausal women. Whether certain subgroups of women (eg, equol producers) do benefit from soy intervention remains to be elucidated.

SK-K was responsible for the data collection and analysis and the draft of the manuscript. LK was responsible for the data collection and analysis and the critical revision of the manuscript. MLB was responsible for the quality of the vascular measurements and the critical revision of the manuscript. JWL was responsible for the genistein and equol assessments and the critical revision of the manuscript. DEG was responsible for the conception and design of the study, for obtaining funding, and for the critical revision of the manuscript. YTvdS was responsible for the conception and design of the study, for obtaining funding, for the supervision of the data collection and analysis, and for the critical revision of the manuscript. There were no conflicts of interest to disclose. The Solae Company neither controlled nor influenced the contents of the research of this paper nor played any part in the decision to submit this manuscript for publication.

\section{REFERENCES}

1. Nagata C. Ecological study of the association between soy product intake and mortality from cancer and heart disease in Japan. Int J Epidemiol 2000;29:832-6.

2. Boker LK, van der Schouw YT, de Kleijn MJ, Jacques PF, Grobbee DE, Peeters PH. Intake of dietary phytoestrogens by Dutch women. J Nutr 2002;132:1319-28.

3. Chen Z, Zheng W, Custer LJ, et al. Usual dietary consumption of soy foods and its correlation with the excretion rate of isoflavonoids in overnight urine samples among Chinese women in Shanghai. Nutr Cancer 1999;33:82-7.

4. van der Schouw YT, Pijpe A, Lebrun CE, et al. Higher usual dietary intake of phytoestrogens is associated with lower aortic stiffness in postmenopausal women. Arterioscler Thromb Vasc Biol 2002;22:1316-22.

5. Squadrito F, Altavilla D, Morabito N, et al. The effect of the phytoestrogen genistein on plasma nitric oxide concentrations, endothelin-1 levels and endothelium dependent vasodilation in postmenopausal women. Atherosclerosis 2002;163:339-47.

6. Cuevas AM, Irribarra VL, Castillo OA, Yanez MD, Germain AM. Isolated soy protein improves endothelial function in postmenopausal hypercholesterolemic women. EurJ Clin Nutr 2003;57:889-94.
7. Squadrito F, Altavilla D, Crisafulli A, et al. Effect of genistein on endothelial function in postmenopausal women: a randomized, doubleblind, controlled study. Am J Med 2003;114:470-6.

8. Hale G, Paul-Labrador M, Dwyer JH, Merz CN. Isoflavone supplementation and endothelial function in menopausal women. Clin Endocrinol (Oxf) 2002;56:693-701.

9. Simons LA, von Konigsmark M, Simons J, Celermajer DS. Phytoestrogens do not influence lipoprotein levels or endothelial function in healthy, postmenopausal women. Am J Cardiol 2000;85:1297-301.

10. Teede HJ, Dalais FS, Kotsopoulos D, Liang YL, Davis S, McGrath BP. Dietary soy has both beneficial and potentially adverse cardiovascular effects: a placebo-controlled study in men and postmenopausal women. J Clin Endocrinol Metab 2001;86:3053-60.

11. Steinberg FM, Guthrie NL, Villablanca AC, Kumar K, Murray MJ. Soy protein with isoflavones has favorable effects on endothelial function that are independent of lipid and antioxidant effects in healthy postmenopausal women. Am J Clin Nutr 2003;78:123-30.

12. Kok L, Kreijkamp-Kaspers S, Grobbee DE, van der Schouw YT. Design and baseline characteristics of a trial on health effects of soy protein with isoflavones in postmenopausal women. Maturitas 2004;47:21-9.

13. Klipstein-Grobusch K, den Breeijen JH, Goldbohm RA, et al. Dietary assessment in the elderly: validation of a semiquantitative food frequency questionnaire. Eur J Clin Nutr 1998;52:588-96.

14. Voorrips LE, Ravelli AC, Dongelmans PC, Deurenberg P, Van Staveren WA. A physical activity questionnaire for the elderly. Med Sci Sports Exerc 1991;23:974-9.

15. de Roos NM, Bots ML, Katan MB. Replacement of dietary saturated fatty acids by trans fatty acids lowers serum HDL cholesterol and impairs endothelial function in healthy men and women. Arterioscler Thromb Vasc Biol 2001;21:1233-7.

16. van Venrooij FV, van de Ree MA, Bots ML, Stolk RP, Huisman MV, Banga JD. Aggressive lipid lowering does not improve endothelial function in type 2 diabetes: the Diabetes Atorvastatin Lipid Intervention (DALI) Study: a randomized, double-blind, placebo-controlled trial. Diabetes Care 2002;25:1211-6.

17. Liang Q, Wendelhag I, Wikstrand J, Gustavsson T. A multiscale dynamic programming procedure for boundary detection in ultrasonic artery images. IEEE Trans Med Imaging 2000;19:127-42.

18. Bots ML, Remme WJ, Luscher TF, Grobbee DE. PERindopril-Function of the Endothelium in Coronary Artery Disease Trial: the PERFECT study-sub study of EUROPA: rationale and design. Cardiovasc Drugs Ther 2002;16:227-36.

19. de Kleijn MJ, Wilmink HW, Bots ML, et al. Hormone replacement therapy and endothelial function. Results of a randomized controlled trial in healthy postmenopausal women. Atherosclerosis 2001;159: 357-65.

20. de Roos NM, Bots ML, Schouten EG, Katan MB. Within-subject variability of flow-mediated vasodilation of the brachial artery in healthy men and women: implications for experimental studies. Ultrasound Med Biol 2003;29:401-6.

21. Wang GJ, Lapcik O, Hampl R, et al. Time-resolved fluoroimmunoassay of plasma daidzein and genistein. Steroids 2000;65:339-48.

22. Brouwers E, L'homme R, Al Maharik N, et al. Time-resolved fluoroimmunoassay for equol in plasma and urine. J Steroid Biochem Mol Biol 2003;84:577-88.

23. Setchell KD, Brown NM, Lydeking-Olsen E. The clinical importance of the metabolite equol-a clue to the effectiveness of soy and its isoflavones. J Nutr 2002;132:3577.

24. Lieberman EH, Gerhard MD, Uehata A, et al. Estrogen improves endothelium-dependent, flow-mediated vasodilation in postmenopausal women. Ann Intern Med 1994;121:936-41.

25. McCrohon JA, Adams MR, McCredie RJ, et al. Hormone replacement therapy is associated with improved arterial physiology in healthy postmenopausal women. Clin Endocrinol (Oxf) 1996;45:435-41.

26. Holm P, Andersen HL, Andersen MR, Erhardtsen E, Stender S. The direct antiatherogenic effect of estrogen is present, absent, or reversed, depending on the state of the arterial endothelium - a time course study in cholesterol-clamped rabbits. Circulation 1999;100:1727-33.

27. Radomski MW, Palmer RM, Moncada S. Endogenous nitric oxide inhibits human platelet adhesion to vascular endothelium. Lancet 1987;2: 1057-8.

28. Kubes P, Suzuki M, Granger DN. Nitric oxide: an endogenous modulator of leukocyte adhesion. Proc Natl Acad Sci U S A 1991;88:4651-5. 
29. De Caterina R. Endothelial dysfunctions: common denominators in vascular disease. Curr Opin Clin Nutr Metab Care 2000;3:453-67.

30. Garg UC, Hassid A. Nitric oxide-generating vasodilators and 8-bromocyclic guanosine monophosphate inhibit mitogenesis and proliferation of cultured rat vascular smooth muscle cells. J Clin Invest 1989;83: $1774-7$.

31. Hogg N, Kalyanaraman B, Joseph J, Struck A, Parthasarathy S. Inhibition of low-density lipoprotein oxidation by nitric oxide. Potential role in atherogenesis. FEBS Lett 1993;334:170-4.

32. Russell KS, Haynes MP, Caulin-Glaser T, Rosneck J, Sessa WC, Bender JR. Estrogen stimulates heat shock protein 90 binding to endothelial nitric oxide synthase in human vascular endothelial cells. Effects on calcium sensitivity and NO release. J Biol Chem 2000;275:5026-30.

33. Guetta V, Quyyumi AA, Prasad A, Panza JA, Waclawiw M, Cannon RO III. The role of nitric oxide in coronary vascular effects of estrogen in postmenopausal women. Circulation 1997;96:2795-801.

34. Caulin-Glaser T, Garcia-Cardena G, Sarrel P, Sessa WC, Bender JR. 17 beta-estradiol regulation of human endothelial cell basal nitric oxide release, independent of cytosolic $\mathrm{Ca}^{2+}$ mobilization. Circ Res 1997;81: 885-92.

35. Russell KS, Haynes MP, Sinha D, Clerisme E, Bender JR. Human vascular endothelial cells contain membrane binding sites for estradiol, which mediate rapid intracellular signaling. Proc Natl Acad Sci U S A 2000;97:5930-5.
36. Squadrito F, Altavilla D, Squadrito G, et al. Genistein supplementation and estrogen replacement therapy improve endothelial dysfunction induced by ovariectomy in rats. Cardiovasc Res 2000;45:454-62.

37. Martin DS, Breitkopf NP, Eyster KM, Williams JL. Dietary soy exerts an antihypertensive effect in spontaneously hypertensive female rats. Am J Physiol Regul Integr Comp Physiol 2001;281:R553-60.

38. Nevala R, Vaskonen T, Vehniainen J, Korpela R, Vapaatalo H. Soy based diet attenuates the development of hypertension when compared to casein based diet in spontaneously hypertensive rat. Life Sci 2000 ; 66:115-24.

39. Rivas M, Garay RP, Escanero JF, Cia P Jr, Cia P, Alda JO. Soy milk lowers blood pressure in men and women with mild to moderate essential hypertension. J Nutr 2002;132:1900-2.

40. Jenkins DJ, Kendall CW, Jackson CJ, et al. Effects of high- and lowisoflavone soyfoods on blood lipids, oxidized LDL, homocysteine, and blood pressure in hyperlipidemic men and women. Am J Clin Nutr. 2002;76:365-72.

41. Hodgson JM, Puddey IB, Beilin LJ, et al. Effects of isoflavonoids on blood pressure in subjects with high-normal ambulatory blood pressure levels: a randomized controlled trial. Am J Hypertens 1999;12:47-53.

42. Hijmering M, Stroes ES, Pasterkamp G, Sierevogel M, Banga JD, Rabelink TJ. Variability of flow mediated dilation: consequences for clinical application. Atherosclerosis 2001;157:369-73. 